\title{
Analisis Kebutuhan Mode Deactivation Counseling untuk Mengendalikan Agresivitas Seksual Siswa Sekolah Menengah Pertama Inklusi
}

(Need Analysis for Mode Deactivation Counseling to Control the Sexual Aggressiveness of Inclusive Secondary School Students)

\section{Muya Barida*, Dian Ari Widyastuti}

Program Studi Bimbingan dan Konseling, Fakultas Keguruan dan Ilmu Pendidikan, Universitas Ahmad Dahlan, Jalan Ringroad Selatan, Bantul, Daerah Istimewa Yogyakarta, 55191, Indonesia

*corresponding author, email: muya.barida@bk.uad.ac.id

Article received: November $23^{\text {rd }} 2019$; revised: April $2^{\text {nd }} 2020$; accepted: April $13^{\text {th }} 2020$

\begin{abstract}
This study seeks to analyze the description of the need for Mode Deactivation Counseling (MDC) as an effort to control adolescent sexual aggressiveness. The research method used literature study and quantitative approach through a survey of 27 inclusive secondary school counselor across several regions in Indonesia. The MDC literature study rested on Mode Deactivation Therapy (MDT), while the survey results were analyzed through descriptive statistical analysis techniques by looking at the categorization of school counselors' answers. The results show that school counselors need an effective way to control adolescent sexual aggressiveness and this can be done through the application of MDC.
\end{abstract}

Keywords: mode deactivation counseling; mode deactivation therapy; sexual aggression; adolescent; inclusive secondary school

\begin{abstract}
Abstrak: Penelitian ini berupaya untuk menganalisis deskripsi kebutuhan $M D C$ sebagai upaya untuk mengendalikan agresivitas seksual remaja. Metode penelitian digunakan studi literatur dan pendekatan kuantitatif melalui survei kepada 27 guru bimbingan dan konseling (BK) yang tersebar di beberapa wilayah Indonesia. Studi literatur $M D C$ berpijak pada $M D T$, sedangkan hasil survei dianalisis melalui teknik analisis statistik deskriptif dengan melihat kategorisasi dari jawaban guru BK. Hasil penelitian menunjukkan bahwa guru BK memerlukan suatu cara efektif untuk mengendalikan agresivitas seksual remaja dan hal ini dapat ditempuh melalui penerapan $M D C$.
\end{abstract}

Kata kunci: $M D C ; M D T$; agresivitas seksual; remaja; SMP inklusi 


\section{PENDAHULUAN}

Berdasarkan perspektif psikologi sosial, perilaku kekerasan seksual merupakan salah satu bentuk perilaku agresi yang ditujukan kepada objek sasaran perilaku. Perilaku agresi merupakan perilaku individu atau sekelompok orang yang diniatkan untuk menyakiti objek sasaran perilaku agresi (Colman, 2015; Hanurawan, 2010). Pelaku perilaku agresi memiliki tendensi untuk merugikan orang lain. Oleh sebab itu, dalam konteks perilaku kekerasan seksual, perilaku agresi seksual didefinisikan sebagai perilaku agresi yang ditujukan pada aspek-aspek yang berhubungan dengan karakteristik seksual orang atau kelompok lain yang menjadi objek sasaran (Hanurawan, 2014). Seseorang yang melakukan kekerasan seksual telah menentukan target yang menjadi objek perusakan.

Fenomena perilaku kekerasan seksual semakin marak terjadi di Indonesia. Kekerasan seksual merupakan masalah perilaku individu sekaligus masalah sosial yang dapat menyebabkan dampak buruk bagi pelaku, korban, teman, keluarga, bahkan komunitas. Bentuk kekerasan seksual di ranah privat/ personal tertinggi yang banyak dilaporkan yaitu incest (pelaku orang terdekat yang masih memiliki hubungan keluarga) sebanyak 1.210 kasus, kedua adalah kasus perkosaan sebanyak 619 kasus, dan ketiga adalah kasus persetubuhan/eksploitasi seksual sebanyak 555 kasus (Komnas Perempuan, 2017). Pelaku kekerasan seksual di ranah personal ada tiga kategori tertinggi yaitu 1.528 kasus oleh pacar, 425 kasus oleh ayah kandung, dan 322 kasus oleh paman. Di ranah publik/komunitas, kekerasan seksual menempati peringkat pertama sebanyak 2.670 kasus (76\%) dibandingkan bentuk kekerasan lainnya. Tiga bentuk kekerasan seksual tertinggi di ranah komunitas antara lain pencabulan (911 kasus), pelecehan seksual (708 kasus), dan perkosaan (669 kasus). Komisioner Komisi Perlindungan Anak Indonesia (KPAI), Listyarti, (2019) mengatakan bahwa sekolah belum sepenuhnya aman dari kekerasan seksual karena banyak kasus kekerasan seksual terjadi di sekolah. Pelaku maupun korban agresi seksual di sekolah pun beragam, mulai siswa-siswa di sekolah reguler maupun siswa-siswa di sekolah inklusi.

Sekolah inklusi memberikan akomodasi bagi siswa berkebutuhan khusus untuk mengikuti pendidikan bersama dengan anak-anak normal lainnya, mulai dari jenjang sekolah dasar hingga sekolah menengah. Sekolah inklusi memberikan akses kepada semua siswa termasuk anak berkebutuhan khusus untuk mengenyam pendidikan yang layak berdasarkan Permendiknas RI Nomor 70 Tahun 2009 tentang pendidikan inklusif bagi siswa yang memiliki kelainan dan memiliki potensi kecerdasan dan/atau bakat istimewa (Direktorat Pembinaan Pendidikan Khusus dan Layanan Khusus Pendidikan Dasar, 2015). Sekolah inklusi yang selayaknya memberikan lingkungan nyaman dan layanan yang lebih unggul sesuai kebutuhan siswa dibandingkan sekolah reguler, pada kenyataannya belum mampu melaksanakannya dengan optimal. Individu berkebutuhan khusus sangat rentan menjadi korban pelecehan seksual karena mereka dianggap sulit untuk melakukan perlawanan dan berkomunikasi (Eastgate et al., 2011), dalam konteks sekolah. Hal ini dapat diperburuk dengan kurangnya pengetahuan guru mengenai pendidikan seks (Yektaoglu-Tomgüsehan \& Akçamete, 2017).

Adanya perubahan paradigma sekolah reguler ke sekolah inklusi membawa dampak juga dalam hal agresivitas seksual (Felicitas, 2016). Perilaku disfungi yang siswa lakukan diperoleh dari pembentukan identitas diri pada masa siswa yang dipengaruhi oleh anteseden, tingkat kualitas proses eksplorasi dan komitmen, serta status identitasnya berada pada domain kehidupan yang berbeda (Purwadi, 2004). Perilaku disfungsi juga bisa terjadi karena siswa meniru apa yang dilihat atau dicontohnya dari suatu model (Barida, 2016). Kurangnya kemampuan self-management juga dapat membuat siswa di sekolah melakukan perilaku yang maladaptif (Barida et al., 2019; Widyastuti \& Muyana, 2019).

Penelitian ini bertujuan melakukan analisis kebutuhan terhadap pengembangan pendekatan konseling $M D C$ untuk mengendalikan agresivitas seksual remaja di Sekolah Menengah Pertama (SMP) inklusi Indonesia. $M D C$ perlu dikembangkan untuk memenuhi kebutuhan di sekolah karena tingginya agresivitas siswa baik secara fisik maupun verbal. Pada sekolah inklusi, siswa berkebutuhan khusus yang merupakan minoritas, sering dibully atau dirugikan oleh teman-teman lainnya (Blake et al., 2012, 2016; Swearer et al., 2012).

$M D T$ diterapkan dan kembangkan untuk remaja dengan gangguan perilaku reaktif dan/ atau gangguan kepribadian, yang memiliki riwayat pelecehan, penelantaran, dan diagnosis multi-aksial yang rumit, yaitu remaja yang merupakan korban pelecehan seksual, fisik, dan/atau emosional, serta, pengabaian (Apsche \& Ward Bailey, 2004). MDT secara empiris terbukti mampu mereduksi agresivitas seksual pada remaja yang mengalami gangguan perilaku dan kepribadian (Apsche, 2010; Apsche et al., 
2006, 2007a, 2007b, 2008; Apsche, Bass, Jennings, \& Siv, 2005; Apsche, Bass, Jennings, Murphy, et al., 2005; Hollman, 2010; Swart et al., 2014; Thoder \& Cautilli, 2011). Berdasarkan keberfungsian dan keefektifan dari $M D T$, maka studi kebutuhan terhadap $M D C$ dalam rangka mengatasi agresivitas seksual siswa di sekolah inklusi perlu dilakukan.

\section{METODE}

Pada awalnya, peneliti melakukan studi literatur tentang Model MDT sebagai dasar dalam mengembangkan $M D C$ agar dapat dianalisis kemenarikan, keberfungsian, dan kebermaknaannya dalam layanan konseling. Penelitian ini melakukan studi kebutuhan $M D C$ yang didukung dengan kajian teori-teori untuk selanjutnya dilakukan pengembangan $M D C$ dan belum menghasilkan suatu produk. Penelitian ini menggunakan pendekatan kuantitatif melalui survei untuk melakukan analisis kebutuhan $M D C$ agar peneliti mampu menghindarkan subjektifitas terhadap jawaban yang memiliki fleksibilitas tinggi dari responden atas pertanyaan-pertanyaan yang diajukan.

Subjek penelitian terdiri dari guru BK yang tersebar di beberapa wilayah di Indonesia, yaitu Jawa Tengah, Jawa Timur, Daerah Istimewa Yogyakarta, Kalimantan Timur, Kalimantan Selatan, Sulawesi Tengah, Sulawesi Tenggara, Bali, dan Nusa Tenggara Barat yang dipilih dengan teknik purposive random sampling. Kriteria purposive, berdasarkan wawancara singkat bahwa sekolah-sekolah tempat guru BK mengabdi di wilayah-wilayah ini, menerima siswa berkebutuhan khusus yang mampu dididik dan dilatih, antara lain siswa slow learner dan gifted. Peneliti memilih guru-guru BK sebagai responden penelitian yang mengikuti Program Profesi Guru (PPG) di Universitas Ahmad Dahlan Yogyakarta pada tahun 2019. Guru-guru ini telah terbukti lulus mengikuti beasiswa PPG yang diselenggarakan oleh pemerintah. Berdasarkan tingkat kemauan dan kemampuan, maka guru-guru ini dapat dikatakan lebih siap dan mampu untuk mengembangkan kapasitas sebagai guru profesional. Dari 68 guru, peneliti mengacak 30 guru sebagai responden penelitian untuk mengisi instrumen kuesioner, namun yang dapat dianalisis adalah 27.

Instrumen yang digunakan yaitu Kuesioner Deskripsi Kebutuhan Mode Deactivation Counseling bagi Guru BK yang berupa pertanyaan tentang pengalaman dan kondisi nyata tentang pendekatan konseling untuk mengatasi agresivitas seksual remaja yang dialami guru BK di SMP inklusi tempat dimana mereka bekerja. Kuesioner dikembangkan melalui proses uji validasi oleh ahli konseling dan perilaku remaja di sekolah inklusi. Berdasarkan serangkaian pernyataan yang disusun dan diajukan, diperoleh 9 butir pernyataan yang dianggap representatif disertai alternatif jawaban rating scale (untuk butir dengan sifat favorable: Sangat Setuju $=$ skor 4, Setuju $=$ skor 3, Tidak Setuju $=$ skor 2, dan Sangat Tidak Setuju $=$ skor 1; untuk butir dengan sifat unfavorable: Sangat Setuju $=$ skor 1, Setuju $=$ skor 2, Tidak Setuju $=$ skor 3, dan Sangat Tidak Setuju $=$ skor 4). Pada Kuesioner Deskripsi Kebutuhan Mode Deactivation Counseling bagi Guru BK butir pernyataan nomor 1, 2, 3 merupakan butir dengan sifat unfavorable dan butir pernyataan nomor 4, 5, 6, 7, 8, dan 9 merupakan butir dengan sifat favorable. Peneliti juga menyediakan kolom di sebelah rating scale apabila responden ingin mendeskripsikan informasi dalam bentuk verbal. Secara lebih jelas, butir pernyataan kuesioner disajikan pada tabel 1 .

Tabel 1. Butir Pernyataan Kuesioner Deskripsi Kebutuhan MDC bagi Guru BK

\begin{tabular}{cl}
\hline No & \multicolumn{1}{c}{ Pernyataan } \\
\hline 1 & Saya lebih memberikan nasihat kepada siswa ketika konseling \\
2 & Saya jarang menerapkan teknik konseling kekinian dalam konseling \\
3 & Siswa-siswa banyak yang melakukan gaya berpacaran yang melebihi batas \\
4 & Saya memerlukan pendekatan konseling yang modern \\
5 & Saya memerlukan pendekatan konseling yang praktis untuk mengatasi masalah seksualitas siswa \\
6 & Saya memerlukan pendekatan konseling yang manjur untuk mengatasi masalah seksualitas siswa \\
7 & Bagi saya, penting dilakukan menggali perspektif siswa tentang pengalaman seksualitas mereka \\
8 & Bagi saya, penting dilakukan untuk mendorong siswa secara sadar mengakui kekeliruan terhadap \\
& pengalaman seksualitas mereka \\
9 & Bagi saya, penting untuk mendorong siswa mengarahkan kembali pikiran, sikap, maupun perilaku keliru \\
& dalam pengalaman seksualitas mereka \\
\hline
\end{tabular}


Data yang terkumpul kemudian dianalisis melalui teknik analisis statistik deskriptif menggunakan kategorisasi. Berdasarkan hasil kategorisasi data, dapat diuraikan bahwa: (1) Kategori rendah, apabila skor total kurang dari $18(\mathrm{X}<18)$; (2) Kategori sedang, apabila skor total lebih dari 18 dan kurang dari $27(18 \leq X<27)$; dan (3) Kategori tinggi, apabila skor total lebih dari $27(X \geq 27)$.

\section{HASIL}

Hasil pengumpulan data disajikan pada tabel 2, dan penghitungan dengan rumus statistik deskriptif melalui bantuan program SPSS disajikan pada tabel 3. Dari hasil analisis statistik deskriptif, dapat diketahui bahwa jumlah responden $(\mathrm{N})$ sebanyak 30 orang, jumlah skor minimum yaitu 22 dan skor maksimum 35, sementara range atau selisih skor minimum dan maksimum sebesar 13. Rata-rata skor kebutuhan terhadap pendekatan $M D C$ sebesar 27,48 dengan standar deviasi sebesar 2,82. Berdasarkan hasil kategorisasi data, dapat diuraikan bahwa: (1) kategori rendah, apabila skor total kurang dari 18 (X $<18$ ); (2) kategori sedang, apabila skor total lebih dari 18 dan kurang dari $27(18 \leq \mathrm{X}<27)$; dan (3) kategori tinggi, apabila skor total lebih dari $27(\mathrm{X} \geq 27)$. Hasil kategorisasi ditampilkan pada gambar 1. Gambar 1 menunjukkan bahwa tidak ada guru BK yang menyatakan bahwa $M D C$ tidak dibutuhkan, sementara 53\% guru BK menyatakan bahwa $M D C$ dibutuhkan dalam kategori sedang, dan $47 \%$ guru BK menyatakan bahwa $M D C$ dibutuhkan dalam kategori tinggi. Akan tetapi, apabila melihat rata-rata skor

Tabel 2. Hasil Pengumpulan Data

\begin{tabular}{|c|c|c|c|c|c|c|c|c|c|c|}
\hline \multirow[t]{2}{*}{ Responden } & \multicolumn{9}{|c|}{ Butir } & \multirow[t]{2}{*}{ Skor Total } \\
\hline & 1 & 2 & 3 & 4 & 5 & 6 & 7 & 8 & 9 & \\
\hline 1 & 3 & 3 & 4 & 3 & 3 & 3 & 3 & 3 & 3 & 28 \\
\hline 2 & 3 & 3 & 2 & 3 & 3 & 3 & 3 & 3 & 4 & 27 \\
\hline 3 & 3 & 3 & 1 & 4 & 3 & 3 & 3 & 3 & 4 & 27 \\
\hline 4 & 3 & 1 & 1 & 3 & 2 & 4 & 2 & 4 & 4 & 24 \\
\hline 5 & 2 & 1 & 1 & 4 & 3 & 3 & 3 & 4 & 4 & 25 \\
\hline 6 & 3 & 4 & 2 & 3 & 3 & 3 & 3 & 3 & 3 & 27 \\
\hline 7 & 4 & 3 & 2 & 4 & 3 & 3 & 3 & 3 & 3 & 28 \\
\hline 8 & 4 & 3 & 4 & 4 & 4 & 3 & 3 & 4 & 4 & 33 \\
\hline 9 & 2 & 2 & 4 & 3 & 3 & 3 & 3 & 3 & 3 & 26 \\
\hline 10 & 3 & 3 & 3 & 3 & 3 & 4 & 3 & 4 & 4 & 30 \\
\hline 11 & 3 & 3 & 3 & 3 & 4 & 4 & 3 & 4 & 4 & 31 \\
\hline 12 & 1 & 3 & 3 & 3 & 3 & 4 & 3 & 3 & 3 & 26 \\
\hline 13 & 3 & 3 & 3 & 3 & 3 & 4 & 3 & 3 & 4 & 29 \\
\hline 14 & 3 & 3 & 2 & 3 & 3 & 3 & 3 & 3 & 4 & 27 \\
\hline 15 & 2 & 3 & 3 & 3 & 2 & 3 & 3 & 3 & 3 & 25 \\
\hline 16 & 3 & 3 & 3 & 3 & 3 & 3 & 3 & 3 & 3 & 27 \\
\hline 17 & 4 & 3 & 4 & 4 & 4 & 4 & 4 & 4 & 4 & 35 \\
\hline 18 & 2 & 3 & 4 & 4 & 4 & 4 & 3 & 3 & 3 & 30 \\
\hline 19 & 2 & 3 & 3 & 4 & 2 & 3 & 4 & 3 & 4 & 28 \\
\hline 20 & 2 & 3 & 3 & 4 & 4 & 4 & 3 & 3 & 4 & 30 \\
\hline 21 & 3 & 3 & 3 & 3 & 3 & 3 & 3 & 3 & 3 & 27 \\
\hline 22 & 3 & 3 & 2 & 3 & 3 & 3 & 3 & 3 & 3 & 26 \\
\hline 23 & 2 & 2 & 2 & 4 & 4 & 4 & 4 & 3 & 3 & 28 \\
\hline 24 & 3 & 2 & 4 & 3 & 3 & 2 & 2 & 2 & 2 & 23 \\
\hline 25 & 2 & 3 & 2 & 3 & 3 & 2 & 2 & 2 & 3 & 22 \\
\hline 26 & 3 & 3 & 3 & 3 & 3 & 3 & 2 & 3 & 3 & 26 \\
\hline 27 & 2 & 2 & 1 & 4 & 4 & 3 & 3 & 4 & 4 & 27 \\
\hline
\end{tabular}


Tabel 3. Hasil Perhitungan Descriptive Statistics

\begin{tabular}{|c|c|c|c|c|c|c|c|c|}
\hline & \multirow{2}{*}{$\begin{array}{c}N \\
\text { Statistic }\end{array}$} & \multirow{2}{*}{$\begin{array}{c}\text { Range } \\
\text { Statistic }\end{array}$} & \multirow{2}{*}{$\begin{array}{c}\text { Minimum } \\
\text { Statistic }\end{array}$} & \multirow{2}{*}{$\begin{array}{c}\text { Maximum } \\
\text { Statistic }\end{array}$} & \multicolumn{2}{|c|}{ Mean } & \multirow{2}{*}{$\begin{array}{c}\begin{array}{c}\text { Std. } \\
\text { Deviation }\end{array} \\
\text { Statistic }\end{array}$} & \multirow{2}{*}{$\begin{array}{l}\text { Variance } \\
\text { Statistic }\end{array}$} \\
\hline & & & & & Statistic & Std. Error & & \\
\hline $\begin{array}{l}\text { Skor Total } \\
\text { Analisis } \\
\text { Kebutuhan } \\
M D C\end{array}$ & 27 & 13 & 22 & 35 & 27,48 & 0,543 & 2,820 & 7,952 \\
\hline $\begin{array}{l}\text { Valid N } \\
\text { (list wise) }\end{array}$ & 27 & & & & & & & \\
\hline
\end{tabular}

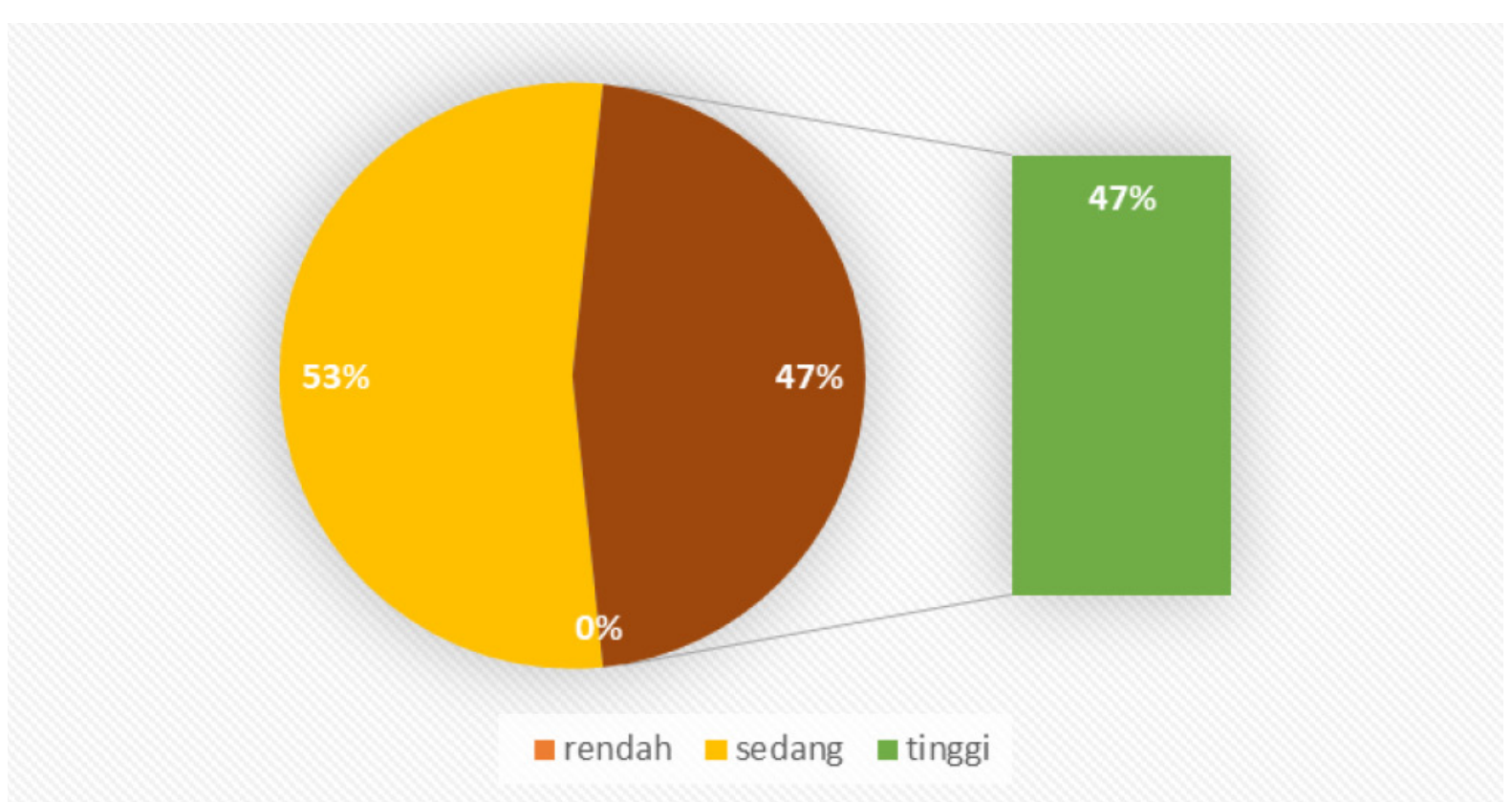

\section{Gambar 1. Hasil Kategorisasi Analisis Kebutuhan MDC untuk Mengendalikan Agresivitas Seksual Remaja}

kebutuhan terhadap pendekatan $M D C$ sebesar 27,48 pada tabel 3, yang artinya bahwa termasuk dalam kategori tinggi $(\mathrm{X} \geq 27)$, dapat diketahui bahwa $M D C$ sebagai pendekatan konseling sangat dibutuhkan untuk mengendalikan agresivitas seksual remaja di SMP inklusi.

\section{PEMBAHASAN}

Kebutuhan untuk mengembangkan model $M D C$ dalam mengatasi masalah agresivitas perlu segera dilakukan. Pernyataan ini dapat dilihat dari jawaban responden pada butir nomor 1, 2, 3, 4, 5, dan 6 . Model konseling yang menarik, berfungsi dan bermakna untuk zaman ini perlu dikembangkan di sekolah inklusi. Oleh karena itu, $M D C$ dikembangkan dengan berpijak pada model MDT. MDT merupakan salah satu dari terapi untuk mengungkap keyakinan diri internal remaja sebelum mengubah perilaku yang tidak tepat. Terapi dilakukan dengan cara membantu remaja mengendalikan reaksi mereka terhadap stimulan alam bawah sadar lalu mengakhiri siklus berkelanjutan dari perilaku yang tertanam dan respon kebiasaan serta memberikan pilihan yang tidak pernah diidentifikasi sebelumnya oleh remaja (Blossom \& Apsche, 2013; Hollman, 2010). Murphy \& Siv, (2011) menambahkan bahwa MDT mencakup serangkaian latihan dengan pikiran penuh kesadaran (mindfullness) yang dirancang khusus bagi remaja, yaitu dengan memastikan keyakinan mereka, meningkatkan kesadaran akan ketakutan, mengurangi kecemasan, dan meningkatkan komitmen untuk mengubah perilaku agresif. Komponen inti dari $M D T$ adalah mindfulness, penerimaan, defusi dan validasi, klarifikasi dan pengalihan keyakinan alternatif fungsional (Apsche, 2010). 
MDT sebenarnya merupakan kombinasi Cognitive Behavior Therapy, Functional Analytic Behavior Therapy, dan Dialectical Behavior Terapy (Apsche, Bass, Jennings, Murphy, et al., 2005). Sementara Bass \& Apsche, (2013) menyebutkan bahwa MDT mengadaptasi komponen-komponen utama Cognitive Behavior Therapy, Acceptance and Commitment Therapy, Dialectical Behavior Therapy, Functional Analytic Psychotherapy and Mindfulness, serta meditasi Buddhisme kuno. Model MDT bertujuan untuk mengubah kognisi/ afeksi/ perilaku destruktif remaja agar lebih fungsional, terarah dan realistis. MDT terdiri dari tiga langkah inovatif untuk mengubah kognisi/afeksi/perilaku sebelumnya secara praktis, yaitu validation, clarification, dan redirection (Apsche et al., 2008). Validation yaitu memberikan umpan balik kepada remaja bahwa cara pandangnya berdasarkan pengalamannya terhadap dunia yang selama ini dia pikirkan, rasakan,dan lakukan merupakan suatu hal yang wajar. Clarification yaitu mengajak remaja untuk berpikir kembali, apakah pengalaman-pengalamannya tersebut telah membelokkan pandangannya tentang dunia. Redirection yaitu mengajak remaja untuk berpikir kembali bahwa kemungkinan hal-hal yang kurang ekstrem atau hal-hal yang lebih seimbang itu lebih realistis.

Konsep utama dan teknik $M D T$ semuanya dirancang untuk memfasilitasi proses perubahan dan mengarah pada pengembangan dan implementasi metodologi sistematis yang sama sekali tidak eklektik, tetapi secara khusus ditargetkan pada proses berpikir bermasalah yang mendasari perilaku disfungsional dan pengalaman batin yang menyedihkan (Swart et al., 2014).

Teknik inti MDT yang dapat diterapkan secara individual maupun kelompok mencakup mindfullness, validasi, defusi emosional dan kognitif, pengalihan kognitif, serta diajarkan untuk memungkinkan pengelolaan diri jauh dari lingkungan terapi. Meskipun tidak ada aturan atau formula ketat yang diinstruksikan, secara umum teknik diterapkan dalam urutan alami yang paling menguntungkan klien, biasanya terdiri dari: kesadaran $\rightarrow$ penerimaan $\rightarrow$ klarifikasi $\rightarrow$ redirection $\rightarrow$ penguatan (Swart et al., 2014).

$M D C$ yang hendak dikembangkan ini terdiri dari tiga tahap utama yaitu VCR (Validation, Clarification, Redirection). Ketiga tahap ini juga telah dimasukkan dalam butir pernyataan Kuesioner Deskripsi Kebutuhan Mode Deactivation Counseling bagi Guru BK pada butir ke-7 untuk aspek Validation, yang berbunyi: "Bagi saya, penting dilakukan menggali perspektif siswa tentang pengalaman seksualitas mereka"; butir ke-8 untuk aspek Clarification, yang berbunyi: "Bagi saya, penting dilakukan untuk mendorong siswa secara sadar mengakui kekeliruan terhadap pengalaman seksualitas mereka"; dan butir ke-9 untuk aspek Redirection, yang berbunyi: "Bagi saya, penting untuk mendorong siswa mengarahkan kembali pikiran, sikap, maupun perilaku keliru dalam pengalaman seksualitas mereka".

Proses konseling $M D C$ seperti yang disajikan pada gambar 2 dimulai dari kegiatan Validation, yaitu mengajak remaja untuk secara sadar menyadari pengalaman yang selama ini dilakukan dari agresivitas seksualnya dan menerima itu sebagai hal yang wajar. Tahap selanjutnya adalah kegiatan Clarification, yaitu mengajak remaja untuk merenungkan kembali apakah agresivitas seksual yang dimilikinya selama ini menguntungkan bagi diri dan kehidupannya. Tahap selanjutnya adalah kegiatan Redirection, yaitu mengajak remaja untuk mengalihkan dan mengarahkan perilaku agresifnya pada perilaku yang lebih berfungsi dan realistis sesuai kebutuhan dan pilihan hidupnya yang positif. Adanya pilihan alternatif remaja untuk mengubah agresivitas seksual kepada hal-hal yang lebih fungsional perlu diberikan penguatan atau reinforcement agar perubahannya komprehensif.
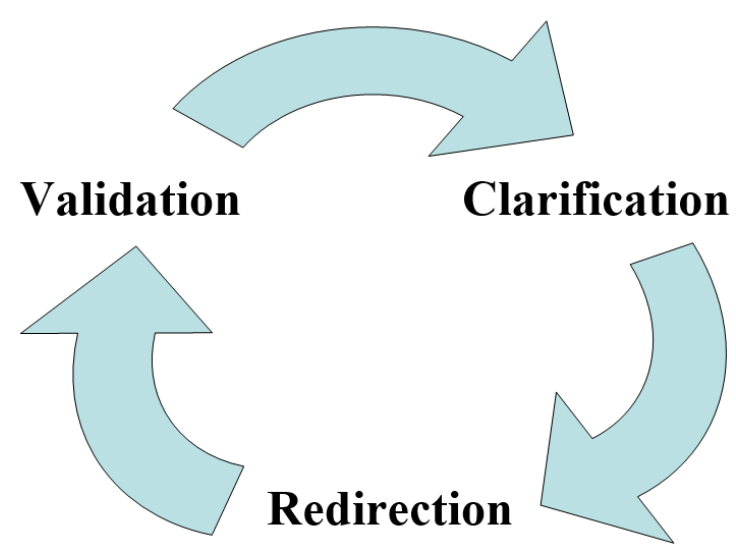

Gambar 2. Proses Konseling Pendekatan MDC 
$M D C$ dirasa sesuai diterapkan dalam layanan BK di Indonesia, karena kultur budaya Indonesia yang memiliki rasa sosial dan kekeluargaan yang tinggi. Apsche et al., (2008) menyatakan bahwa MDT dapat digunakan pada diri remaja secara individual maupun pada latar keluarga. Pendekatan ini menggabungkan strategi treatment dari perilaku, kognitif, dialektika dan pendekatan psikoterapi pendukung lainnya yang diberikan secara sistematis melalui metode yang jelas. Keunggulan ini juga telah diukur oleh Apsche et al., (2006) dari segi hasil setelah treatment yang mengungkap bahwa dibandingkan dengan Cognitive Behavior Therapy dan Social Skill Training, pendekatan ini lebih memiliki efek generalisasi positif dalam diri konseli untuk mereduksi agresi fisik dan seksual.

\section{SIMPULAN}

Berdasarkan hasil pembahasan, $M D C$ dapat dikembangkan dan diterapkan pada lingkup SMP inklusi sebagai jawaban terhadap kebutuhan guru BK akan penanganan siswa yang bermasalah dalam agresivitas seksual. $M D C$ memiliki kelebihan dari segi kepraktisan bagi Guru BK untuk membantu siswa mengatasi kecenderungan agresivitas seksual mereka. Selain itu, $M D C$ mampu memberdayakan siswa untuk secara aktif melakukan validation, clarification, dan redirection pengalaman serta kondisi nyata agresivitas seksual yang mereka lakukan, sehingga menemukan pilihan hidup yang lebih fungsional.

\section{DAFTAR RUJUKAN}

Apsche, J. A. (2010). A literature review and analysis of mode deactivation therapy. International Journal of Behavioral Consultation and Therapy, 6(4), 296-340.

Apsche, J. A., Bass, C. K., \& Houston, M.-A. (2007a). Family MDT: vs. treatment as usual in a community setting. International Journal of Behavioral Consultation and Therapy, 3(1), 145-153.

Apsche, J. A., Bass, C. K., \& Houston, M.-A. (2007b). Family mode deactivation therapy as a manualized cognitive behavioral therapy treatment. The Behavior Analyst Today, 8(3), 363-378.

Apsche, J. A., Bass, C. K., Jennings, J. L., Murphy, C. J., Hunter, L. A., \& Siv, A. M. (2005). Empirical comparison of three treatments for adolescent males with physical and sexual aggression: Mode deactivation therapy, cognitive behavior therapy and social skills training. International Journal of Behavioral Consultation and Therapy, 1(2), 101-113.

Apsche, J. A., Bass, C. K., Jennings, J. L., \& Siv, A. M. (2005). A review and empirical comparison of two treatments for adolescent males with conduct and personality disorder: Mode Deactivation Therapy and Cognitive Behavior Therapy. International Journal of Behavioral Consultation and Therapy, 1(1), $27-45$.

Apsche, J. A., Bass, C. K., \& Siv, A. M. (2006). Summary of Mode Deactivation Therapy, Cognitive Behavior Therapy and Social Skills Training with two year post treatment results. International Journal of Behavioral Consultation and Therapy, 2(1), 29-44.

Apsche, J. A., Bass, C. K., Zeiter, J. S., \& Houston, M. A. (2008). Family mode deactivation therapy in a residential setting: Treating adolescents with conduct disorder and multi-axial diagnosis. International Journal of Behavioral Consultation and Therapy, 4(4), 328-339.

Apsche, J. A., \& Ward Bailey, S. R. (2004). Mode deactivation therapy (MDT) family therapy: A theoretical case analysis. Journal of Early and Intensive Behavior Intervention, 1(2), 191-217.

Barida, M. (2016). Pengembangan perilaku anak melalui imitasi. Jurnal CARE (Children Advisory Research and Education), 3(3), 13-20.

Barida, M., Prasetiawan, H., Sutarno, S., \& Muarifah, A. (2019). The development of self-management technique for improving students' moral intelligence. International Journal of Educational Research Review, 4(4), 660-669.

Bass, C. K., \& Apsche, J. A. (2013). Mediation analysis of mode deactivation therapy (reanalysis and interpretation). International Journal of Behavioral Consultation and Therapy, 8(2), 1-6.

Blossom, P., \& Apsche, J. (2013). Effects of loneliness on human development. International Journal of Behavioral Consultation and Therapy, 7(4), 28-29.

Colman, A. M. (2015). A dictionary of psychology. Oxford Quick Reference.

Direktorat Pembinaan Pendidikan Khusus dan Layanan Khusus Pendidikan Dasar. (2015) Permendiknas, R I No. 70 Tahun 2009 tentang pendidikan inklusif bagi siswa yang memiliki kelainan dan memiliki potensi kecerdasan dan/atau bakat istimewa. 
Eastgate, G., Van Driel, M. L., Lennox, N., \& Scheermeyer, E. (2011). Women with intellectual disabilities: a study of sexuality, sexual abuse and protection skills. Australian Family Physician, 40(4), 226.

Felicitas, M. (2016). Sekolah inklusi untuk jamin hak pendidikan korban kekerasan seksual dan narkoba. https:// www.tribunnews.com/regional/2016/06/27/sekolah-inklusi-untuk-jamin-hak-pendidikan-korban-kekerasanseksual-dan-narkoba

Hanurawan, F. (2010). Psikologi sosial suatu pengantar. Remaja Rosdakarya.

Hanurawan, F. (2014). Prevensi psikologi sosial terhadap perilaku kekerasan seksual dalam komunitas. Seminar Nasional Pendekatan Integratif Pendidikan Seksual Dalam Menyiapkan Generasi Emas Indonesia.

Hollman, J. (2010). Accentuating Mode Deactivation Therapy (MDT): A review of a comprehensive meta-analysis into the effectiveness of MDT. International Journal of Behavioral Consultation and Therapy, 6(4), 395-397.

Komnas Perempuan. (2017). Tergerusnya ruang aman perempuan dalam pusaran politik populisme. In Catatan Kekerasan terhadap Perempuan Tahun 2017.

Listyarti, R. (2019). KPAI sebut sekolah belum sepenuhnya aman dari kekerasan seksual. http://jatengpos.co.id/ kpai-sebut-sekolah-belum-sepenuhnya-aman-dari-kekerasan-seksual

Murphy, C. J., \& Siv, A. M. (2011). A one year study of mode deactivation therapy: Adolescent residential patients with conduct and personality disorders. International Journal of Behavioral Consultation and Therapy, 7(1), 32-39. https://doi.org/10.1037/h0100924

Purwadi, P. (2004). Proses pembentukan identitas diri remaja. Humanitas: Indonesian Psychological Journal, $1(1), 43-52$.

Swart, J., Winters, D., \& Apsche, J. (2014). Mindfulness-based mode deactivation therapy for adolescents with behavioral problems and complex comorbidity: Concepts in a nutshell and cost-benefit analysis. Journal of Psychology \& Clinical Psychiatry, 1(5), 00031. https://doi.org/10.15406/jpcpy.2014.01.00031

Thoder, V. J., \& Cautilli, J. D. (2011). An independent evaluation of mode deactivation therapy for juvenile offenders. International Journal of Behavioral Consultation and Therapy, 7(1), 40-45.

Widyastuti, D. A., \& Muyana, S. (2019). The influence of self-management in using gadgets against nomophobia in adolescents. International Conference on Social Science and Character Educations (IcoSSCE 2018) and International Conference on Social Studies, Moral, and Character Education (ICSMC 2018), 53-56.

Yektaoglu-Tomgüsehan, T., \& Akçamete, G. (2017). Examining the opinions of teachers of adolescent students with mental deficiencies towards sexual education. Eurasia Journal of Mathematics, Science and Technology Education, 14(1), 323-335. 